\title{
Profissionalização em empresas familiares: os desafios da implementação de governança corporativa numa empresa do setor de transportes
}

Henrique Cordeiro Martins ${ }^{1}$

Alysson Pierre Pires De Almeida ${ }^{1}$

Otto Herman Pedreira Goecking ${ }^{1}$

${ }^{1}$ UNIVERSIDADE FUMEC 


\section{PROFISSIONALIZAÇÃO EM EMPRESAS FAMILIARES: OS DESAFIOS DA IMPLEMENTAÇÃO DE MECANISMOS DE GOVERNANÇA CORPORATIVA NUMA EMPRESA DO SETOR DE TRANSPORTES}

Resumo: Tornar as empresas de tipificação familiar mais competitivas e com bom nível de gestão é um desafio a qualquer empreendedor e, ao mesmo tempo, fundamental para continuidade dos negócios e manutenção do controle da família sobre a empresa. Porém, observa-se a dificuldade de profissionalização nas empresas familiares, bem como adoção de boas práticas de governança corporativa. O objetivo desse artigo é analisar os aspectos que facilitam e/ou dificultam a adoção de boas práticas de governança corporativa numa empresa familiar do setor de transporte, a partir do seu processo de profissionalização. Para tanto, esse trabalho utiliza métodos de pesquisa de natureza qualitativa e quantitativa em uma organização familiar que se encontra na segunda geração e está em processo de profissionalização. Os resultados apontam que o processo de implementação de governança corporativa pode ser dificultado ou facilitado por características de gestão que incluem, principalmente, os aspectos culturais, direção e sucessão.

Palavras-chave: Empresas Familiares. Profissionalização. Governança Corporativa.

\section{Introdução}

Empresas de tipificação familiar são exemplos de instituições com características peculiares que têm sérias dificuldades em perceber o contexto em que os seus negócios atuais estão inseridos. Contudo, essas empresas possuem grande representatividade econômica e social em qualquer parte do mundo.

No entanto, Gersick et al (1997) acreditam que as empresas administradas por famílias constituem uma forma organizacional particular cujo "caráter especial" tem consequências positivas e negativas. Essas peculiaridades podem trabalhar contra o profissionalismo do comportamento empresarial. Antigas histórias e dinâmicas familiares podem se intrometer nos relacionamentos de negócios e, por isso, pode ser mais difícil exercer autoridade com os parentes e os papéis na família e na empresa podem tornar-se confusos. As pressões da empresa podem sobrecarregar e destruir relacionamentos familiares e quando o trabalho perde em eficiência, criam-se níveis de tensão, raiva, confusão e desespero que são capazes destruir, de forma surpreendentemente rápida, boas empresas e famílias sadias.

A profissionalização das empresas familiares, tanto na ótica da propriedade, quanto da gestão, é um processo que organiza e atenua o impacto dos aspectos peculiares dessas organizações que dificultam não só sua competitividade, mas também a sua própria sobrevivência. Se precisasse escolher até cinco pontos-chave relacionados com a continuidade das empresas familiares ao longo do tempo, certamente estaria entre eles a profissionalização (CASILLAS et al., 2007).

O processo de profissionalização abrange, dentre outras variáveis, um dos principais problemas das empresas familiares: o processo sucessório. Segundo Bernhoeft (2005), esse processo tem relação direta com a sobrevivência e a expansão do próprio negócio. Outro ponto importante é a separação da propriedade, gestão e família, um dos conceitos fundamentais de

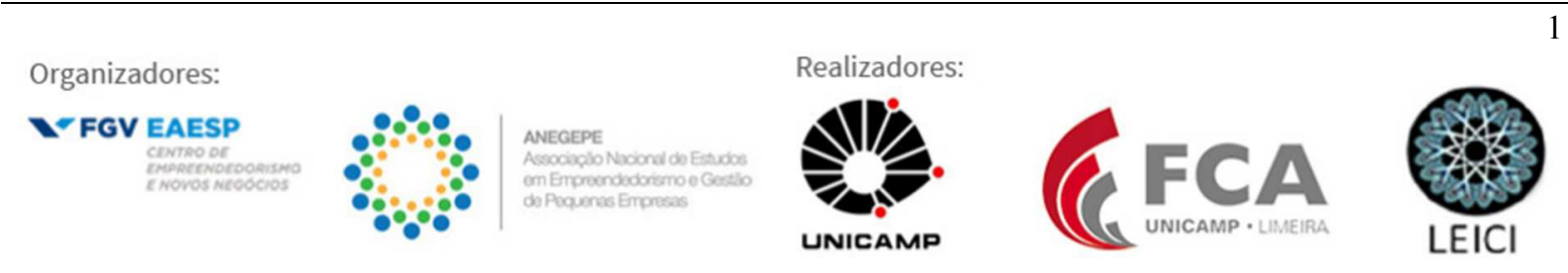


governança familiar e uma "evolução" da governança corporativa para as especificidades identificadas nessa tipificação de empresa.

Nesse sentido, a governança corporativa (GC) pode ser utilizada como um instrumento valioso para a condução do processo de profissionalização da empresa familiar. Bornholdt (2010) comenta que em função da complexidade exposta, das sobreposições e dos conflitos de interesses, juntamente com as relações afetivas e de consanguinidade citadas sob a ótica empresarial-familiar por Gersick et al. (1997), a governança nas empresas familiares passa a ser um dos temas de maior relevância para vários campos do conhecimento. Isso deve-se fundamentalmente, segundo Bornholdt (2010), aos escândalos em empresas de todo o mundo, em especial nos Estados Unidos, no Japão e Itália; o desaparecimento, a falência ou a venda de um alto número de empresas familiares na transição entre uma geração e outra; em função de embates, de desavenças e brigas entre familiares, dentro e fora da empresa; o enriquecimento desproporcional dos acionistas controladores quando detentores do poder de gestão; ou dos gestores em geral, quando externos.

Fica evidente para a maioria dos autores que pesquisam empresas familiares que o processo de sucessão é um dos principais e mais complexos problemas na continuidade da empresa familiar. Oliveira (2012), por exemplo, acredita que se o desenvolvimento desse processo pode não apresentar bons resultados esperados. Mas para que esse processo ocorra de forma adequada, Werner (2008) defende que toda sucessão exige administração e planejamento conduzidos pela família. Sem a participação ativa da família, certamente a não consolidação dos valores necessários para o processo não acontecerá. Desse modo, a profissionalização dos sócios destacada por Adachi (2010), além da profissionalização da gestão, se torna imprescindível para o êxito do processo de sucessão e, concomitantemente, para perpetuidade das empresas familiares.

Se de um lado, a dificuldade de profissionalização e da condução do processo sucessório é latente nas empresas familiares, de outro lado, a adoção de boas práticas de GC nesse tipo de empresa pode facilitar esses processos nas organizações familiares. Nesse sentido, os estudos em organizações que estão passando por esse momento vêm contribuir para a perenidade dessas companhias. Há, inclusive, um gap na literatura que associe os constructos governança corporativa, profissionalização e sucessão em empresas familiares. Dessa forma, é passível de se questionar: quais são os aspectos facilitadores e/ou dificultadores da adoção de boas práticas de governança corporativa a partir do processo de profissionalização nas empresas familiares?

Para responder a essa questão, o objetivo desse artigo foi analisar os aspectos que facilitam e/ou dificultam a adoção de boas práticas de governança corporativa numa empresa familiar do setor de transporte, a partir do seu processo de profissionalização.

Esse tema se justifica tendo em vista que a complexidade no processo de sucessão ocorre em função das expectativas e anseios individuais dos seus donos, principalmente da segunda para terceira geração. A governança das empresas familiares trata de normas e regras entre os diferentes interesses em torno de uma cultura organizacional formada ao longo da história. Assim, os aspectos de GC aplicados à empresa familiar podem ajudar a definir as normas e regras entre os interesses individuais e os coletivos, o que incide num difícil processo de renúncias por parte dos donos (BORNHOLDT, 2010). Portanto, entender as dificuldades e limitações existentes na gestão das empresas familiares é um ponto importante no seu processo

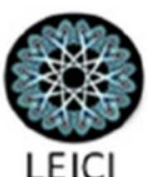


de profissionalização e utilização das boas práticas de governança. Além disto, há a representatividade expressiva das empresas familiares no mundo inteiro e também no Brasil.

Além desta introdução, este artigo apresenta o referencial teórico que sustenta os argumentos, a metodologia da pesquisa, a análise dos resultados e as considerações finais.

\section{Referencial Teórico}

\section{1 - Empresa Familiar: concepções, abordagens e alcance}

O conceito de empresa familiar é compreendido de diversas visões na literatura que trata do assunto. Adachi (2010) argumenta que nas definições de empresa familiar não existe qualquer restrição quanto à área de atuação da empresa, quanto ao seu tamanho, quanto à formatação jurídica da sociedade ou com relação ao tempo de existência. O ponto crucial que caracteriza uma empresa familiar, em sua opinião, é a influência que a família exerce sobre o controle societário e dos negócios. CASILLAS et al.,(2007) apontam que a maioria dos conceitos de empresas familiares gira em torno de três aspectos que equivalem às três características que servem para delimitar, na prática, as empresas familiares: a) propriedade ou o controle sobre a empresa; b)o poder exercido pela família sobre a empresa, normalmente pelo trabalho nela desempenhado por alguns membros da família; c)a intenção de transferir a empresa a futuras gerações e a concretização disso na inclusão de membros dessa nova geração na própria empresa.

Desde 1998, Lodi já argumentava que não é novidade que as empresas familiares representam a grande maioria das organizações tanto no Brasil quanto na Europa e são responsáveis por uma empregabilidade também considerável (LODI, 1998). Assim, a solução dos problemas apresentados por essas empresas também é importante para o desenvolvimento desses países. Werner (2008), por exemplo, comenta sobre a gestão centralizada como sendo um dos pontos negativos das empresas familiares. Ele acredita que as características centralizadoras do empreendedor nem sempre são ideais para enfrentar os desafios da continuidade. Ao contrário, podem ser um problema, dado que as equipes de trabalho deixam de aprender a decidir e passam a confiar apenas na habilidade do empreendedor, sem compartilhar responsabilidades.

Após descrever a diferenciação entre a empresa familiar e família empresária, a afetividade envolvida nas empresas familiares que as torna diferentes das demais e a falta de códigos que regulem as relações entre família e empresa, o estudo discute o modelo clássico e de grande aceitação por parte dos estudiosos, consultores e interessados no assunto: o Modelo de Três Círculos da empresa familiar. Este modelo surgiu baseado em um estudo elaborado por Tagiuri e Davis no início da década de 1980, em que eles sugeriram que o retrato preciso de toda a diversidade de empresas familiares precisaria fazer uma distinção crítica entre os subsistemas de propriedade e de gerenciamento dentro do círculo da empresa. O entendimento era que algumas pessoas são proprietárias, mas não estão envolvidas na operação da empresa. Outras são gerentes, mas não controlam ações. Os estudos realizados por Gersik et al. (1997) reforçaram o argumento que os dilemas enfrentados pelas empresas familiares, por exemplo, as empresas controladas por primos, teria mais a ver com a distinção entre proprietários e gerentes do que entre a família e a gestão como um todo.

Gersick et al. (1997) explicam que o modelo descreve o sistema da empresa familiar como três subsistemas independentes, mas superpostos: gestão, propriedade e família. Qualquer
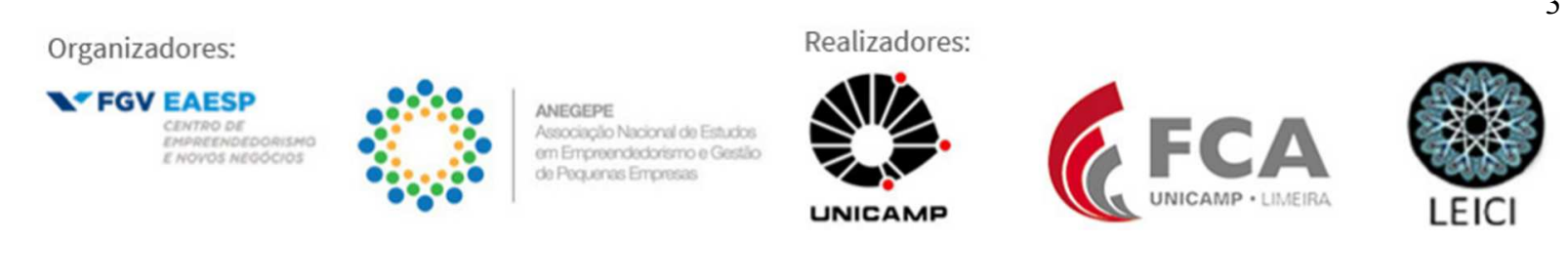
pessoa em uma empresa familiar pode ser colocada em um dos sete setores formados pelos círculos superpostos dos subsistemas. As pessoas com mais de uma ligação com a empresa estarão em um dos setores superpostos, que se enquadram dentro de dois ou três círculos ao mesmo tempo. Com essa clareza, a ferramenta é muito útil para a compreensão da fonte de conflitos interpessoais, dilemas de papéis, prioridades e limites em empresas familiares. Essa é uma das razões a qual o modelo teve uma aceitação ampla, ou seja, pela sua aplicabilidade imediata.

\section{2 - Especificidades da Profissionalização e Sucessão}

Casillas et al. (2007) analisa a profissionalização em dois aspectos distintos, os quais ele faz questão de separar. O primeiro refere-se ao caráter externo ou interno (familiar ou nãofamiliar) dos membros que exercem cargos de direção nas empresas familiares. No outro aspecto, esse termo relaciona-se à existência de uma estrutura organizacional e de gestão, em que prevaleçam os valores empresariais e a formação e capacitação idônea de seus dirigentes para o cargo que exercem, pertencendo ou não à família proprietária. Esse último é o conceito que os autores defendem como o significado correto do termo profissionalização. Dessa forma, a profissionalização depende: dos princípios e valores que prevalecem na empresa; da existência de uma estrutura e de um modelo organizacional e empresarial; dos profissionais que exercem cargos de alguma responsabilidade executiva na empresa, pois devem ser apropriadas, quanto ao nível e à orientação da formação, capacitação profisssional, aptidões e atitudes.

Amendolara (2005) acredita que a profissionalização está vinculada a forma como a empresa familiar é estruturada do ponto de vista de poder, ou seja, como os proprietários detentores do controle acionário exercem o poder na organização e como funciona seu relacionamento com o conselho de administração e a diretoria executiva.

O processo de profissionalização da empresa familiar passa necessariamente pelo aspecto da sucessão. Para Tondo et al. (2005), sucessão é a transferência de poder nas decisões empresariais, de conhecimento e conclui-se com a transferência de patrimônio entre gerações. De acordo com Leone (2005), a sucessão não é algo que pode ser resolvida da noite para o dia. É um processo longo que tem como alicerce o planejamento e a organização. Por um lado, o sucessor deve se preparar para o cargo. Por outro, o sucedido deve tornar esse processo o mais claro possível, informando à família os detalhes de como ele está encaminhando a escolha.

Baseado no modelo de Bayad e Barbot (2002), Lima et al. (2007) abordam e comentam que a sucessão em empresas familiares não se restringe a um fato gerencial. Cabe envolver dois elementos que estão em jogo: de um lado a transmissão de patrimônio e de outro a transmissão gerencial. O modelo proposto por Bayad e Barbot (2002) para descrição do processo sucessório busca demonstrá-lo como resultante de um processo de transmissão gerencial e de transmissão patrimonial, intrinsecamente ligados.

A transmissão gerencial é um processo que se inicia com a entrada do sucessor na empresa geralmente incentivada pelo fundador. O sucessor deve dispor de capacidades empreendedoras e gerenciais suficientes para assegurar a continuidade e o desenvolvimento das atividades na organização (SHARMA; CHRISMAN; CHUVA, 1997). A partir de então, os sucessores passam a examinar suas responsabilidades dentro da empresa, de modo a possibilitar que sua participação efetive a sucessão na organização (ST-CRY; INOUSSA, 2000). A transmissão patrimonial é comumente compreendida como um ato terminal e puramente

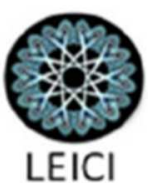


administrativo. Entretanto, a qualidade da relação entre o fundador e o sucessor causa um forte impacto no processo de sucessão (ST-CRY; INOUSSA, 2000). Dois fatores assegurariam seu sucesso: o respeito mútuo entre as gerações e a adaptação de papéis feita pela segunda geração. Para tal, também é relevante a criação de um conjunto de valores comuns entre os envolvidos para se evitar possíveis conflitos.

\section{3 - Governança Corporativa na Empresa Familiar}

Dos conceitos encontrados na literatura, as palavras mais constantes nessas definições são "dirigidas" e "monitorar/controlar". Além disso, as definições também abordam fortemente o relacionamento de poder das organizações na alta administração. Apesar dessa similaridade, as diferenças entre os modelos praticados em diversos países do mundo são provenientes do perfil histórico, cultural, econômico e institucional de cada país em que cada um predomina (ANDRADE e ROSSETTI, 2012).

Para Bornholdt (2010), para entender o sistema empresarial-societário-familiar, a questão principal é compreender as relações interpessoais existentes nesse sistema. Essas relações são tão complexas que, quando se procura estruturá-las, elas remetem aos fundamentos da cultura organizacional. Dessa forma, acredita o autor, que cultura organizacional e governança da empresa familiar são faces da mesma moeda. Ele ainda analisa a governança com vistas à forma de como se organizavam os grupos pertencentes aos povos antigos, o que para ele, é o início do que atualmente chama-se de governança.

O processo de governança em empresas familiares pode ser compreendido por perigos e oportunidades, segundo Bornholdt (2010). Definir as normas e as regras entre os interesses individuais em prol do coletivo (empresa) é fundamentalmente um processo de renúncias. As renúncias da individualidade em prol da identidade familiar (e não por opção) despertam os sentimentos mais contraditórios e ambivalentes, como paixão, ódio, amor, inveja, segurança e resignação. Esses sentimentos se manifestam das mais diferentes formas no seio familiar e empresarial. Apesar dessas dificuldades latentes principalmente nas empresas familiares, é necessário integrar os sistemas da família, da sociedade e da empresa. Para poder integrar essas três dimensões, é preciso inicialmente distanciá-las. Essa distinção permite um entendimento mais apropriado da estrutura e do conteúdo do assunto. E para entender a origem dos possíveis conflitos que rompem a perpetuação das empresas familiares ao longo das gerações, é necessário compreender a estrutura sistêmica da governança familiar. Ela abrange os três eixos e a relação entre os três sistemas: - o sistema empresarial e o conselho de administração (gestão); - o sistema societário e a assembleia de acionistas e sócios (sócios); - o sistema familiar e o conselho de família (famílias).

\section{Metodologia}

O presente trabalho utiliza métodos de pesquisa de natureza qualitativa e quantitativa. No intuito de caracterizar o fenômeno do caso, através da análise de conteúdo da pesquisa qualitativa e dos resultados estatísticos aplicados na pesquisa quantitativa, o tipo de pesquisa adotada é a descritiva. Entende-se que a empresa objeto do estudo atende aos requisitos para o tipo de pesquisa a qual se propõe; a organização é uma empresa familiar que se encontra na segunda geração, sua direção é composta de diretores familiares e não-familiares, ela está em processo de profissionalização e tem familiares alocados na gestão da empresa.

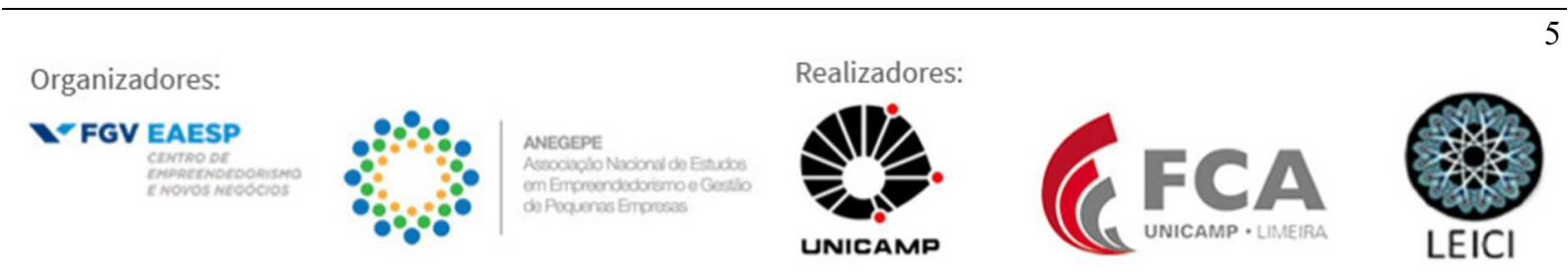


O estudo foi desenvolvido em duas etapas: a primeira etapa foi realizada uma pesquisa qualitativa. Os objetivos qualitativos tratam dos princípios e valores culturais da organização, da adoção de práticas de governança corporativa e dos aspectos que dificultam ou facilitam a implementação dessas práticas no processo de profissionalização da empresa familiar. Para essa etapa, foi utilizada a entrevista semiestruturada, os sujeitos da pesquisa que foram entrevistados correspondem a três diretores estatutários, denominados de D1, D2 e D3, e os dois diretores não-estatutários (D4 e D5), totalizando cinco entrevistas. A análise dos dados dessa etapa foi feita pela técnica análise de conteúdo.

$\mathrm{Na}$ segunda etapa, foi adotada a pesquisa quantitativa para se investigar o estágio de profissionalização da empresa do estudo na visão dos funcionários. Dessa forma, foi utilizada para coleta de dados a aplicação de um questionário. A estrutura do questionário foi elaborada de acordo com a mesma sequência e correspondência aos blocos estruturados no roteiro aplicado aos diretores. Para seleção da amostra foi utilizado o conceito de amostra nãoprobabilística por acessibilidade e dessa forma, o número de funcionários que seriam elegíveis para responder ao questionário foi de 120, de um total de 400 funcionários. As áreas que foram consideradas nesse âmbito foi o Comercial, Operacional Interno e Administrativo. Essa seleção foi necessária uma vez observada que os funcionários não-elegíveis não reuniam condições para responder ao questionário em função da baixa escolaridade e a ausência constante das dependências da empresa. Dos 120 questionários enviados, obteve-se a resposta de 81 funcionários ou $67,50 \%$ do total elegível. Para avaliação do questionário, foi utilizada uma escala ordinal, Escala Likert, a qual foi aplicada em cinco pontos, variando-se incidência ou frequência da seguinte forma: concordo, concordo parcialmente, não concordo/não discordo, discordo parcialmente e discordo. A análise dos dados dessa etapa se deu por meio de técnicas de estatística descritiva.

\section{1 - Descrição do Caso Pesquisado}

A empresa Alfa foi fundada em 1966 por um imigrante espanhol, que veio ao Brasil para se refugiar da II Guerra Mundial. Sem conhecer o ramo de transportes, ele iniciou suas atividades como transportador de cargas, sendo acompanhado por um motorista carreteiro, pois não havia documentos legais para transitar no país. No início, transportava as cargas que ninguém queria. Posteriormente, o fundador participou da construção de Brasília; e a conselho do então Presidente Juscelino Kubitscheck, cortou seu caminhão e o transformou em um cavalo mecânico. Em seguida, comprou uma carreta. Esse foi o início da trajetória do fundador da empresa que se especializou em transporte rodoviário de cargas especiais e indivisíveis, o principal negócio da empresa atualmente. Ainda completam o portfólio atual de serviços os transportes de produtos siderúrgicos, cargas de lotação completa, contâiners, em regime de trânsito aduaneiro, cargas internacionais, em regime de urgência, multimodal, movimentação de cargas (içamento) e escoltas.

Com a entrada da esposa no negócio, a empresa cresceu muito no decorrer dos anos, uma vez que sua experiência profissional era advinda do setor de transportes. Quando veio o fato da separação, os filhos ainda jovens (três atuais diretores) receberam por doação todas as ações da mãe-proprietária e parte do pai-fundador, assumindo desde então, não só a propriedade da empresa, mas também toda a gestão do negócio com o apoio do pai. A partir dessa época, a mãe afastou-se complemente das operações da empresa, dando seu apoio somente em questões

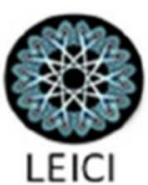


sociais desenvolvidas. De outro relacionamento, o pai-fundador teve um filho que posteriormente ingressou-se na gestão da empresa, recebeu uma doação do pai sem consentimento dos outros sócios (três filhos) e atualmente ocupa uma função de sócio-gerente na empresa. A companheira do segundo relacionamento do pai-fundador nunca teve nenhuma influência direta na propriedade e na gestão da organização.

De acordo com o modelo tridimensional proposto por Gersick et al. (1997), a empresa Alfa está no segundo estágio de desenvolvimento: Sociedade de Irmãos. Portanto, encontra-se na segunda geração. Das cinco diretorias, duas são ocupadas com profissionais não-familiares. As três restantes são ocupadas por membros da família (irmãos) e sócios da empresa com $29,33 \%$ cada. Um desses diretores ocupa o cargo de presidente e diretor comercial. Outro irmão ocupa o cargo de gerente de planejamento logístico e possui $10 \%$ da empresa. Os $2 \%$ restantes das ações ainda pertencem ao sócio-fundador, que não ocupa nenhum cargo na gestão na empresa. Além disso, dois membros da terceira geração (primos) já trabalham na empresa há aproximadamente dois anos.

\section{Apresentação e análise dos resultados}

\section{1 - Parte I - A visão dos Diretores da Empresa}

Destacou-se na estruturação desse bloco algumas particularidades presentes nessa tipologia de empresa, como, por exemplo, a sucessão e a presença de familiares e proprietários na gestão da empresa. Isso possibilitou um melhor entendimento dos diretores em relação à sequência e ao entendimento do assunto a ser pesquisado. As 48 perguntas foram agrupadas da seguinte forma: aspectos culturais (8), aspectos de direção/gestão (10), aspectos de sucessão (10) e aspectos de governança corporativa (20).

Aspectos Culturais: Observou-se que os diretores da Empresa Alfa demonstraram uma coerência e entendimento sobre os princípios e valores da empresa e sobre a forma de agir e pensar da organização, apesar de não se aterem somente aos valores definidos no planejamento estratégico, descrito como: 1. Confiamos em Deus; 2. Valorizamos e respeitamos uns aos outros; 3. Dedicação ao trabalho com foco em resultado; 4. Honramos os nossos compromisso; 5. Agimos com simplicidade. Não obstante, observou-se num comentário do diretor D3 que o processo de profissionalização por qual passa a Empresa Alfa não afeta seus valores, principalmente um dos valores que explicitam a influência direta da família sobre a empresa:

Antes de tudo, nós somos uma família que tem gratidão a DEUS. Por isso, apesar de subjetivo, essa foi uma forma que encontramos que nossos funcionários entendessem que a cultura da empresa, mesmo passando de uma empresa familiar para uma empresa profissional, é importante para nós (Diretor D3).

A Empresa Alfa está na segunda geração há mais de 20 anos. Apesar de uma cultura organizacional ser conduzida e compartilhada pela experiência e realização de aprendizado comum (ADACHI, 2010), nesse caso baseado na cultura da figura do fundador, a visão que os diretores possuem é que não existem atualmente valores na empresa ligados ao fundador, principalmente em função do tempo que a sucessão da gestão e da propriedade foi realizada.

Outro ponto analisado na cultura da Empresa Alfa foi a respeito da questão decisória. A forma como a empresa está organizada e é controlada torna-se um aspecto importante e que afeta diretamente o processo decisório. Apesar da Empresa Alfa está na segunda geração, todos os diretores reconheceram que o atual processo decisório da empresa é centralizado, com exceção do diretor D2. Embora esta concordância exista, os diretores observaram dois fatores
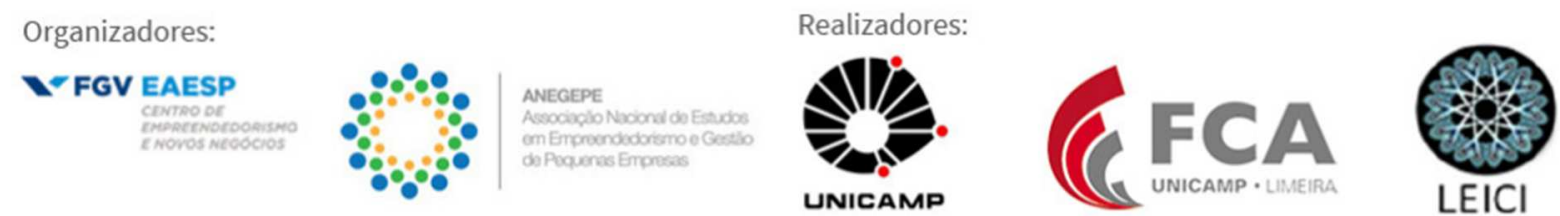
importantes. O primeiro, é que as decisões operacionais já estão sendo tomadas parcialmente pelos gestores das áreas. O segundo, é que existe uma preocupação com a preparação dos gestores da empresa de forma que os mesmos possam responder pela decisão, ou seja, legitimála.

A dificuldade apresentada no processo decisório é resultado da não organização da empresa e da falta de definições das responsabilidades atribuídas a cada gestor, segundo o diretor D4. Tondo et al. (2008) ainda acrescentam que na prática, dentro de empresas familiares, o direito de decisão está, normalmente, alocado junto aos membros da família que possuem cargos de gestores na empresa.

Sobre a análise do tema liderança, também pesquisado junto aos diretores no bloco de aspectos culturais, o diretor D1 reconheceu que ainda é presente na empresa uma liderança centralizadora. Porém, a empresa tem buscado ferramentas para que permitam uma delegação maior. De certa forma, isso se confunde com a questão decisória já trabalhada anteriormente e que se mostra coincidente em sua essência, ou seja, também centralizada. O diretor D3 comenta que a liderança da empresa não é uniforme, ou seja, não existe um conceito difundido de como liderar na organização de acordo com sua cultura. Contudo, adverte que existe na empresa liderança autoritária coincidente com a centralizadora, e liderança democrática, com um conceito de maior participação ativa

Aspectos de Direção: Pelo conceito de empresa familiar citado pela literatura, além da firma está ligada a uma família há mais de duas gerações, a empresa familiar é caracterizada quando essa ligação impacta numa influência recíproca. De acordo com esse conceito, o diretor D2 explicitou essa visão quando perguntado sobre a composição acionária da empresa e a relação dos sócios com a família:

Nós ainda não temos essa separação de sócio ou família, pois ainda temos uma integração. São todos diretamente irmãos e o pai. A composição acionária da empresa atualmente é divida, principalmente, entre os três diretores, com aproximadamente $29 \%$ cada, $10 \%$ para o irmão mais novo e $3 \%$ para o fundador (Diretor D2).

Apesar do discurso acima, em relação ao vínculo dos sócios e família, observou-se um ponto relevante, segundo o diretor $\mathrm{D} 3$, em relação à composição acionária e relação dos sócios com a família: Somos cinco cotistas. O fundador com 3\%, o filho mais velho e os outros dois irmãos com o mesmo número de cotas, e outro sócio cotista que não é diretor com 10\% (Diretor D3).

Se analisado o conteúdo dos dois discursos acima, observa-se que o tratamento dado ao sócio que possui $10 \%$ das cotas é diferente. Enquanto o diretor D2 cita o mesmo pela expressão "irmão mais novo", o diretor D3 o cita como "outro sócio cotista que não é diretor". Foi comentado que esse sócio é fruto de outro relacionamento do fundador, portanto, não fazendo parte da família fundadora. Ainda de acordo com o diretor D3, existe uma separação natural do primeiro núcleo. Isso evidencia que existe um conflito na relação entre alguns acionistas da Empresa Alfa. Outro ponto relevante foi o diretor D5 não ter nenhum conhecimento da composição acionária ou da relação dos sócios com a família.

Contudo, o diretor D5 aborda uma visão diferente sobre a sobreposição de papéis na diretoria e acrescenta o seguinte: Existe, mas entendo e interpreto isso como cunho colaborativo. Existe a sobreposição, sem dúvida. Um exemplo disso é o presidente da empresa também exercer o papel de diretor comercial. 
Fica constatado diante das respostas unânimes, que a empresa não possui um orçamento empresarial. O diretor D4 citou que o orçamento não conseguiu ser realizado porque a empresa não sabe qual a receita será alcançada nesses períodos. Assim, como não se sabe qual é a receita, também não era possível fazer um orçamento de despesa.

Aspectos de Sucessão: As questões sobre os aspectos de sucessão da Empresa Alfa ficaram mais limitados ao desenvolvimento pelos diretores estatutários, apesar dos diretores não-estatutários também terem respondido. Os diretores estatutários responderam que a Empresa Alfa não possui um plano de sucessão formalizado. Entretanto, isso já está sendo trabalhado dentro do processo de governança iniciado no segundo semestre de 2010. O diretor D1 respondeu dessa maneira:

Não existe um plano. Nós estamos trabalhando nisso e nos próximos dois ou três anos acredito que o plano esteja totalmente pronto. Não é um processo fácil de formalizar. Estamos fazendo isso via governança. Com o estabelecimento da governança, que começa agora nesse semestre, assuntos como o conselho da família, o processo de sucessão e os critérios para que isso ocorra de forma transparente [serão discutidos] (Diretor D1).

Pela resposta do diretor D1, a empresa já demonstra preocupação em tratar do assunto de forma clara, transparente e com critérios objetivos, utilizando-se do instrumento de governança para apoiar esse processo. O diretor D2, em sua resposta, apresenta uma visão interessante sobre o processo de sucessão na Empresa Alfa, ao dizer que considera a empresa ainda na primeira geração quando se trata do período de sucesso e maior crescimento da organização. Os diretores não-estatutários responderam que nunca foram apresentados a algum plano de sucessão ou não tinham conhecimento a respeito, acreditando que tal assunto ficasse restrito aos acionistas da empresa.

Para os diretores D1 e D2, ainda não são discutidas as questões relativas aos herdeiros e sucessores junto à família. Já para o diretor D3, também estatutário, isso é um assunto que já é desenvolvido e diz como isso está sendo realizado: "É muito transparente. Eu como responsável pela governança, todas as vezes que faço uma reunião com eles, coloco de forma clara o que é herdeiro e o que é sucessor, principalmente para os que estão trabalhando na empresa" (Diretor D2).

Essa visão do diretor D3 diverge da opinião dos outros diretores estatutários. Apesar do trabalho e dos conceitos apresentados pelo diretor D3 aos membros familiares, isso não é uma prática da família e ainda não tem um trabalho direcionado e preparado nesse sentido, com unidade da empresa versus família. Os diretores D4 e D5 desconhecem qualquer prática de discussão relativa aos herdeiros e sucessores dentro da empresa. Observa-se que existe uma divergência entre as opiniões dos diretores, deixando confusa essa questão das regras para admissão de familiares. Apesar de ter citado um ou dois pontos, não existe uma formalização e se quer uma concordância nesse sentido. Portanto, é uma questão que se demonstra incipiente.

Aspectos de Governança Corporativa: A Empresa Alfa está passando por um processo de implementação de práticas de GC, porém, apesar do plano já estar finalizado, sua implementação iniciou-se somente no segundo semestre de 2010. Dessa forma, algumas perguntas foram respondidas de acordo com o conhecimento do assunto e participação dos diretores estatuários no trabalho de elaboração do plano. Os diretores não-estatutários 
responderam as questões de acordo com seu conhecimento do assunto, uma vez que não participaram da elaboração do plano.

A primeira questão tratou de introduzir o assunto e perguntar o porquê a empresa deveria adotar mecanismos de governança corporativa em seu processo de profissionalização. A resposta que mais obteve afirmação foi a que trata da consciência em torno do assunto. Não obstante, o diretor D2, tenha uma clareza referente ao assunto e define assim:

A governança para mim é muito importante. Hoje ainda os acionistas são os executivos da empresa. E isso deixa mais claro e transparente como um todo, direitos e deveres de ambas as partes. Não só como familiar, como irmão, sobrinho, tio, pai, filho, ou até como diretor em si (Diretor D2).

O diretor D3 afirma que essas partes interessadas são consideradas no planejamento e na gestão da empresa, porém não participam do processo. Apesar do diretor D2 ter uma posição mais forte da não participação ou limitada, juntamente com a opinião do diretor D3, o diretor D1 em seu discurso já é mais flexível à participação, porém cita principalmente a participação dos funcionários.

A Empresa Alfa manterá em seu conselho de administração membros da família, segundo os diretores estatutários. O conselho será formado por todos os sócios cotistas, cinco membros, e outros dois membros externos. Portanto, como a empresa possui atualmente três diretores executivos que também são sócios e irmãos, a organização não vê problemas ter membros familiares no conselho de administração. A visão da empresa nessa questão conflita com o código das melhores práticas do IBGC (2016). Pelo código, no item que trata da composição do conselho de administração, o conceito de representação não poderia estar previsto no plano de governança da Empresa Alfa, tendo em vista que o conselheiro tem seus deveres relacionados à organização e, consequentemente, a todas as partes interessadas na empresa. Sendo os conselheiros da Empresa Alfa membros familiares, executivos da empresa e sócios, essa isenção de interesses se apresenta comprometida. De forma geral, entre os diretores estatutários, a empresa também não vê problemas de o presidente do conselho de administração fazer parte do grupo de controle.

Percebe-se que a Empresa Alfa ainda é carente de sistemas de controle interno. O diretor D5, apesar de reconhecer que não tinha muito conhecimento dessa área, respondeu que acreditava que a empresa tivesse sistemas de controle em todas as áreas, diferentemente dos outros quatro diretores. O mesmo ainda citou que a empresa ainda está se adequando a um crescimento vertiginoso dos últimos anos. Os diretores foram unânimes em dizer que a empresa atualmente não possui um código de conduta por escrito e aprovado pelo conselho de administração ou pela diretoria executiva.

Por fim, procurou-se sintetizar, na visão dos diretores, quais seriam as dificuldades e/ou facilidades que a empresa deve enfrentar na implementação das boas práticas de GC com vistas ao processo de profissionalização a qual passa a Empresa Alfa. Os diretores D1 e D2 apresentaram semelhanças em suas visões e responderam que a empresa terá dificuldades no campo cultural, embora expressadas de forma diferente, são coincidentes. Além disso, salientaram que a implementação da GC no processo de profissionalização deverá ser facilitada diante da vontade e comprometimento de todos os diretores envolvidos nesse plano, como já observado nas reuniões de planejamento. O diretor D3 destaca o fato da empresa não passar atualmente por nenhum processo de conflito e não ter problemas financeiros. Em contrapartida,
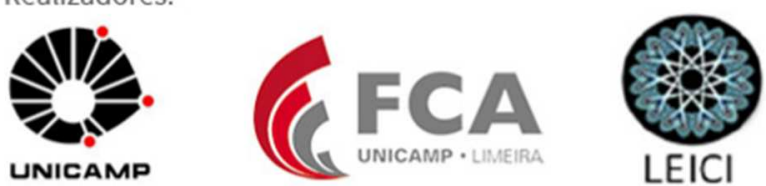
enxerga como uma dificuldade a participação de outro sócio que não faz parte do núcleo principal da família. O diretor D4, por sua vez, ancora sua visão na disponibilidade dos diretores estatutários descentralizarem o poder decisório, opinião também partilhada pelo diretor D5, que não por coincidência, são não-estatutários. O diretor D4 ainda complementa as dificuldades que poderão ser enfrentadas e cita também a desconfiança excessiva dos profissionais que trabalham na empresa.

\section{2 - Parte II - O grau de profissionalização da Empresa na visão dos Funcionários}

No perfil dos funcionários entrevistados considerou-se relevante o tempo de trabalho na empresa, dos quais $62 \%$ dos funcionários que responderam o questionário possuem menos de 3 anos de empresa. Porém, o percentual que representa pouco tempo de trabalho na empresa reflete o período de sua profissionalização e também de sua expansão. Outro aspecto observado ainda no âmbito do perfil dos entrevistados é sobre o nível de formação acadêmica. Do total, $43 \%$ dos funcionários possuem formação acadêmica em graduação tecnológica ou bacharelado.

Aspectos Culturais: Nessa parte da investigação, foram elaboradas questões de forma a identificar quais eram os traços culturais observados pelos funcionários da Empresa Alfa. Observa-se na análise que as perguntas P6 e P9, respectivamente tratando da formalização das atividades e tratamento igualitário entre funcionário familiar e não familiar, obtiveram o menor desempenho entre os funcionários. O resultado apurado dessas duas afirmativas coincide com os apresentados pelos diretores da empresa, mais especificamente o D4 e D5. Dessa forma, a visão dos funcionários é igual à dos diretores da Empresa Alfa nesses dois quesitos. As afirmativas P10 e P11, que tratam de conhecimento do superior imediato e preparação desse superior, respectivamente, foram as únicas que não tiveram apuradas as opções de "Não concordo/Não discordo", ou seja, foram respondidas com mais propriedade pelos funcionários. Contudo, essas mesmas apresentaram os maiores níveis de concordância em aspectos culturais. Portanto, pode-se concluir que os funcionários da Empresa Alfa enxergam que os aspectos culturais presentes na organização estão alinhados com práticas de uma empresa profissionalizada.

Aspectos de Direção: Para esse âmbito, foram elaboradas questões para verificar a visão dos funcionários relativa aos aspectos de direção adotados na empresa. Realizada a análise das afirmativas relativas aos aspectos de direção, observa-se que as respostas, do ponto de vista quantitativo, resultaram num equilíbrio. As afirmativas P16 e P17, que tratam respectivamente da existência do orçamento e acompanhamento e análise do mesmo, apresentaram os menores índices de concordância de todo o questionário, respectivamente 2,5\% e 6,2\%. As mesmas tratam da existência de orçamento empresarial e do acompanhamento, análise e feedback, desse instrumento de gestão, no âmbito da pesquisa, considerado uma prática de empresas profissionalizadas.

A afirmativa P14, que trata do planejamento estratégico, teve uma concordância parcial expressiva de $43,2 \%$ e demonstra coerência com o discurso do diretor D1 ao comentar que tem dúvidas se o planejamento estratégico está difundido claramente para os funcionários da empresa. Em contradição, o resultado da afirmativa P13 distorce essa percepção quando 74,1\% dos funcionários afirmaram que conhecem os objetivos estratégicos os quais eles contribuem. As afirmativas P12 e P15 (conhecimento dos diretores e missão, valores e visão da empresa,
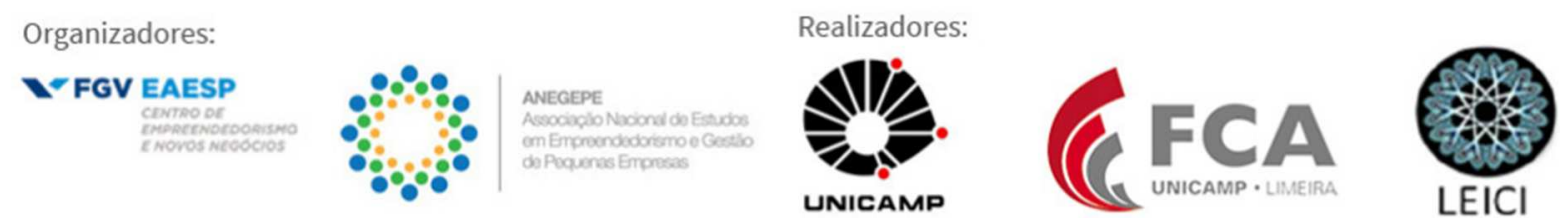
respectivamente) obtiveram um bom índice de concordância e estão de acordo com a opinião dos diretores da empresa de forma geral.

Aspectos de Sucessão: Assim como os diretores D4 e D5, não-estatutários, os funcionários apresentaram algumas dúvidas ou dificuldades de respostas para as afirmativas relativas aos aspectos de sucessão. Isso ficou evidente nos resultados apurados. Os motivos apresentados se situaram pela falta de transparência e ausência de discussão que o assunto é tratado pela empresa. Fica evidenciado pelas afirmativas P18 e P22 (conhecimento do processo de sucessão e existência de órgão formal para tratar de sucessão), respectivamente com 11,1\% e 9,9\% de concordância, que a grande maioria dos funcionários desconhece o processo de sucessão da empresa. A afirmativa P21, que trata da ascensão profissional na empresa baseada na competência, obteve um nível de concordância 40,7\% e se apresenta como bom indicativo para o processo de profissionalização da Empresa Alfa. As afirmativas P19 e P20 situaram-se em níveis baixos de concordância pelos funcionários, tratando as mesmas de regras de contratação e remuneração para funcionários familiares e não-familiares.

Aspectos de Governança Corporativa: Uma afirmativa importante que foi confrontada nos aspectos de governança corporativa era o de verificar a percepção dos funcionários em relação ao processo de profissionalização (P23) que a empresa desenvolve há aproximadamente cinco anos. Segundo a análise da afirmativa P23, 80\% dos funcionários escolheram opções que tenham alguma discordância da afirmação. Portanto, é um percentual bastante expressivo e demonstra que os funcionários não estão percebendo a mudança da empresa em relação ao processo de profissionalização.

A afirmativa P24, que trata dos conhecimentos dos funcionários em relação à governança corporativa, constatou que apenas $37 \%$ dos entrevistados conhecem ou já ouviram falar do tema, demonstrando que esse assunto ainda está no início na empresa, pelo menos na visão dos funcionários, e pode ter prejudicado um pouco as respostas em relação ao tema. Os funcionários entrevistados também desconheceram a adoção de mecanismos de governança corporativa no processo de profissionalização da empresa, conforme desempenho da afirmativa P25. Somente $18,5 \%$ responderam no maior nível de concordância das opções, ou seja, observam que as práticas de governança estão sendo adotadas.

As afirmativas P27, P28 e P29 tratavam respectivamente da existência do Conselho de Administração, do conhecimento dos membros e funções e de encontro periódico. Para 76,5\% dos funcionários a organização não possui um Conselho de Administração, ou seja, escolheram opções que tenham alguma discordância da afirmação. Somente $17,3 \%$ dos entrevistados conhecem os supostos membros do Conselho de Administração e suas funções. E 14,8\% responderam que o Conselho de Administração se reúne periodicamente.

Para a afirmativa P30, apesar de $22,2 \%$ dos funcionários terem a percepção que a empresa utiliza assessoria externa, 77,8\% não acreditam que a empresa utiliza esse tipo de serviço, de acordo com os critérios de análise. Para os diretores, contraditoriamente, a empresa utiliza consultoria externa, porém confundindo com membro externo do Conselho de Administração. Já para a afirmativa P34, os diretores afirmaram que a empresa não possui ainda um Conselho de Família formalmente constituído. As afirmativas P31, P32 e P33, que tratam respectivamente de auditoria externa, sistemas de controles internos e código de conduta, obtiveram bom nível de concordância se comparado aos níveis das outras afirmativas.

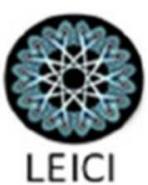


Grau de profissionalização: De acordo com a análise da pontuação dos funcionários, observa-se que a maioria deles tem uma percepção de profissionalização da Empresa Alfa positiva. Isso pode ser confirmado, além da média, também pela mediana. Após a soma da pontuação de cada funcionário, organiza-se a sequência por ordem decrescente e verifica qual é a pontuação que representa a metade quantitativa dessa sequência. Isto significa que metade da amostra teve uma pontuação igual ou acima de 130, enquanto a outra metade, menor que 130. Portanto, essa medida comprova um alto índice de profissionalização na percepção dos funcionários. Desse modo, foi realizada estatística descritiva para cada uma das afirmativas do questionário.

Para investigar se existe diferença entre a percepção dos entrevistados para os atributos investigados, além do resultado geral, foram apurados os resultados levando em consideração cada uma das variáveis de caracterização (unidade de trabalho, idade e nível de formação acadêmica).

Para leitura do Gráfico 01 (bem como do gráfico 02), exemplifica-se a análise que deve ser realizada. Quando as linhas estão próximas indica não haver diferença de opinião (em relação à concordância) entre os grupos. Já quando as linhas estão mais distantes, como por exemplo, na afirmativa $\mathrm{P} 24$, as opiniões são diferentes em relação à concordância. No caso da afirmativa P24, que trata do conhecimento das práticas de governança corporativa no questionário, observa-se que a concordância na matriz (linha azul) é superior à concordância na filial (linha vermelha). Portanto, esse resultado mostra que o entendimento do conceito de governança corporativa é distinto entre a matriz e filial (unidades agrupadas).

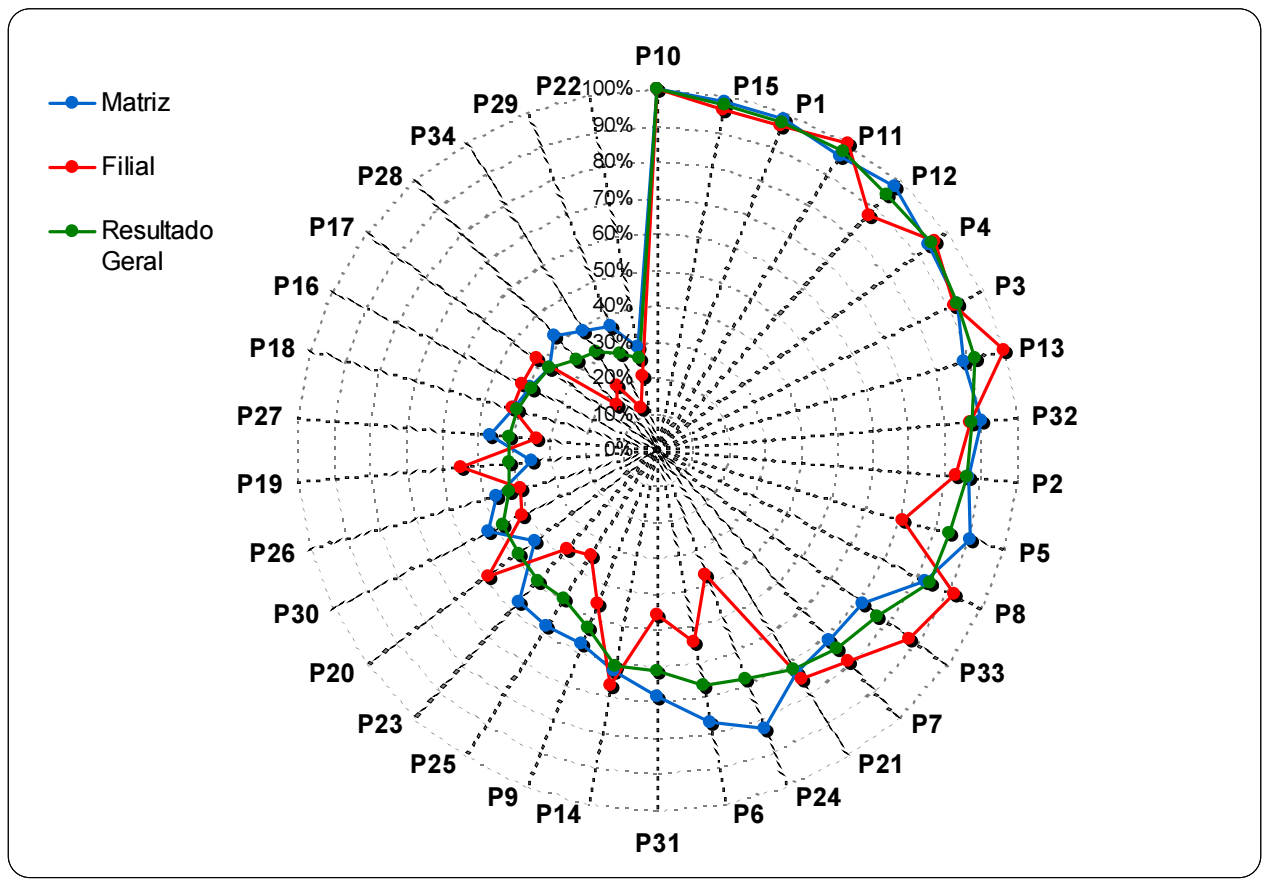

Gráfico 01 - Percentual de concordância por Unidade de Trabalho e Afirmativa

Fonte: Dados da Pesquisa.

Organizadores:

- fov eaesp

Contho of

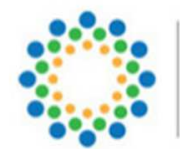

ANEGEPE

Nescivicto Noviond de Estudios

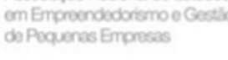
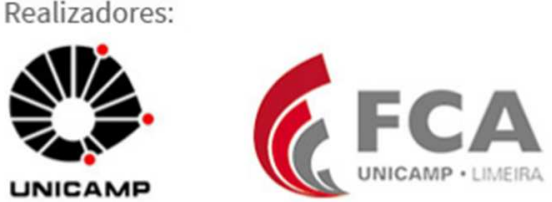
A afirmativa P25, observada no gráfico 1, que trata das práticas de governança corporativa que a empresa está implementando no seu processo de profissionalização, também obteve uma avaliação baixa da filial em relação à matriz. A análise dessas duas afirmativas sugere que o entendimento dos funcionários da matriz em relação aos da filial são maiores. Isso pode ocorrer em função dos mesmos estarem mais próximos das decisões e diretoria da empresa, bem como à necessidade de maior profissionalização. Não obstante, a comunicação da matriz com a filial se mostra incipiente, uma vez observado essas diferenças de conhecimento sobre o assunto.

Outra diferença avaliada são as afirmativas P22, P29, P34 e P28, em que a filial diverge consideravelmente com a matriz, apesar desta última também não apresentar bom nível de concordância. A P22 trata de aspectos de sucessão e as outras três tratam de aspectos de governança corporativa. Fica evidente, observado o baixo grau de concordância da filial nessas afirmativas, que assuntos estratégicos e de gestão estão restritos, e ainda pouco difundidos, no campo da matriz.

Para a análise por nível de formação acadêmica (Gráfico 02), algumas categorias foram agrupadas para melhor visualização dos resultados no gráfico radar. O agrupamento está descrito na legenda do gráfico. Das variáveis de caracterização avaliadas, o nível de formação acadêmica foi o que apresentou maior variação no percentual de concordância. A primeira observação é do resultado geral em relação aos níveis de formação acadêmica. Os níveis do ensino fundamental e ensino médio/técnico apresentaram um maior grau de concordância em relação à média geral, com raras exceções. Já os níveis de graduação tecnológica/bacharelado e pós-graduação demonstraram a maioria das pontuações abaixo do resultado geral.

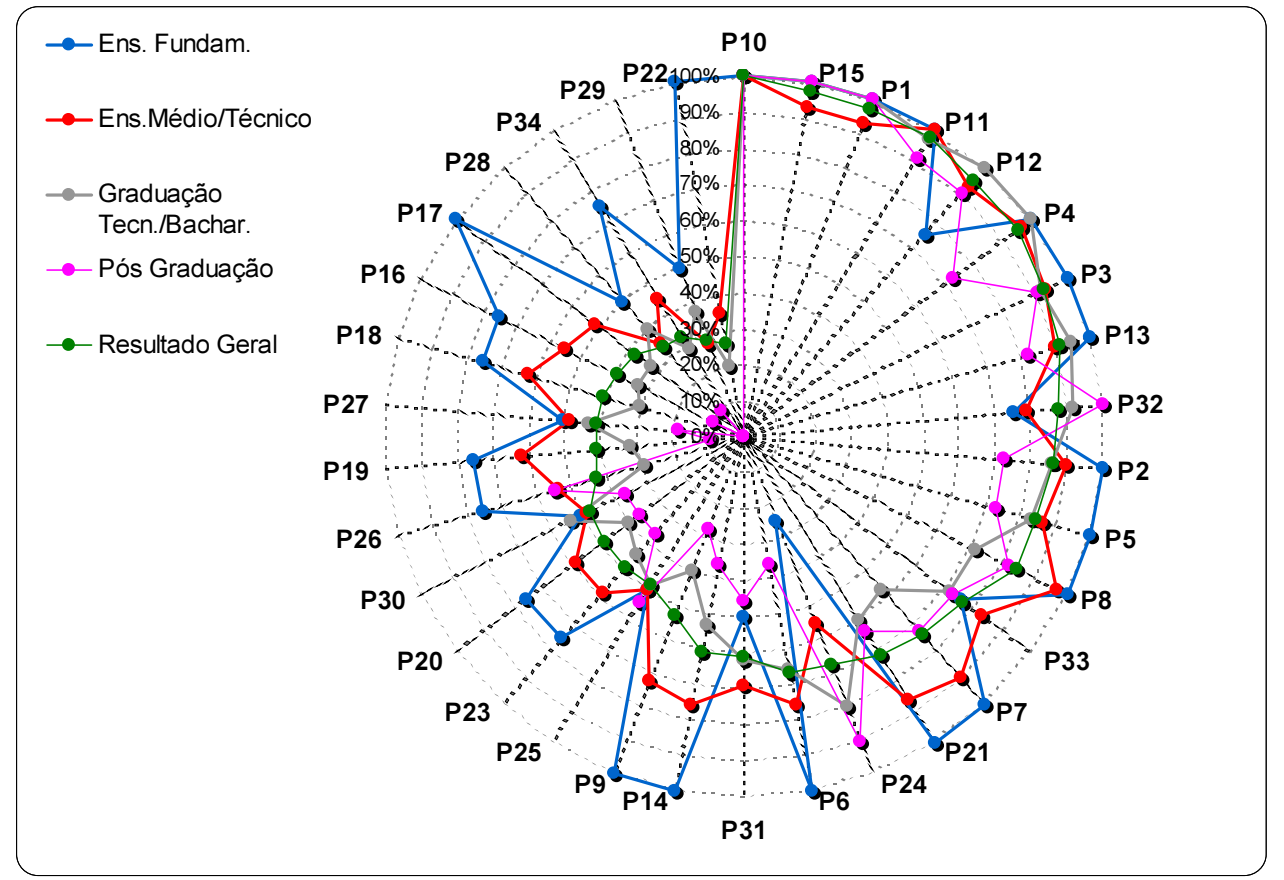

Gráfico 02 - Percentual de concordância por nível de formação acadêmica

Fonte: Dados da Pesquisa.

\section{Organizadores:}
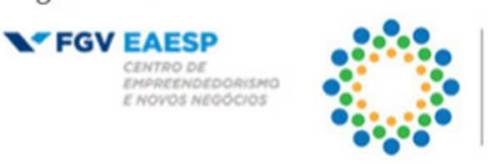

ANEGEPE

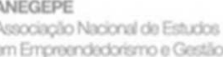

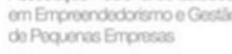

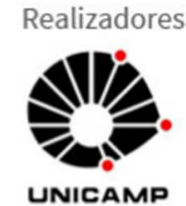

UNICAMP 
Uma observação importante dessa análise é quando se identifica o menor nível de formação acadêmica e o maior nível. Se visto no gráfico, a percepção dos funcionários enquadrados nesses níveis de formação acadêmica é inversamente proporcional. Ou seja, quanto maior o nível de formação, menor o grau de concordância. Quanto menor o nível de formação, maior o grau de concordância. Desta forma, fica evidente que o nível de formação acadêmica dos funcionários da Empresa Alfa afetou a percepção em relação ao grau de profissionalização da organização.

\section{Considerações finais}

Para responder o objetivo geral da pesquisa foi necessário identificar, portanto, os traços do processo de profissionalização que estavam em andamento na empresa para poder avaliar a utilização dos mecanismos de governança nessa etapa. Entretanto, não era suficiente obter somente a percepção da diretoria da organização, mas também a percepção dos funcionários que vivem diariamente os reflexos dessas mudanças.

A maioria dos diretores afirmou que um dos motivos da empresa adotar mecanismos de governança corporativa em seu processo de profissionalização é a consciência do movimento existente em torno do assunto. Essa visão não justifica a adoção de boas práticas de governança, o que demonstra fragilidade no processo da empresa. Com pouca interação com o mercado, a empresa demonstrou dificuldades em participarem da sua gestão os stakeholders. As principais dificuldades apontadas pelos diretores da empresa em adotar mecanismos de GC, situaram-se principalmente na questão cultural, inclusive, destacando a descentralização do poder decisório. Outro aspecto dificultador apontado é a participação de outro sócio (irmão mais novo) que não faz parte do núcleo principal de acionistas, o que contradiz um dos principais conceitos da governança que é a equidade no tratamento dos acionistas. Entre as facilidades, os diretores sugeriram que a vontade e comprometimento de todos os executivos envolvidos nesse plano terão importância na implementação do processo de governança.

Após a análise do resultado da aplicação do questionário aos funcionários, conclui-se que eles percebem que a cultura da empresa se aproxima das práticas de uma empresa profissionalizada, de acordo com os critérios da pesquisa. Já para os aspectos de direção, o nível de concordância com as afirmativas não obteve o mesmo desempenho, apresentando inclusive, os dois menores níveis de concordância de toda a pesquisa. Os aspectos de sucessão foram apresentados com pouco conhecimento por parte dos funcionários e mostra-se principiante na empresa, esse foi um dos assuntos com os piores desempenhos, tanto pelo lado dos diretores quanto pelos funcionários.

As facilidades e dificuldades apresentadas pelos diretores para que a empresa adote mecanismos de GC foram respondidas com certa dificuldade e põe em cheque a real necessidade e aplicabilidade desse processo na empresa, apesar do interesse sobre o assunto. No campo das dificuldades, os pontos apresentados no discurso dos diretores podem colocar em risco a implementação do processo de governança da empresa, uma vez que os conceitos construídos no plano, em sua essência, divergem dos conceitos apresentados pelo código de melhores práticas do IBGC e não justificam o motivo para sua aplicabilidade da forma como está sendo planejada. As facilidades se apresentam com pouco apelo, sendo proclamadas somente pela vontade dos acionistas, situação financeira confortável e uma sugerida ausência de conflitos. Esses fatores, apesar de legítimos, demonstram não ser suficiente para a
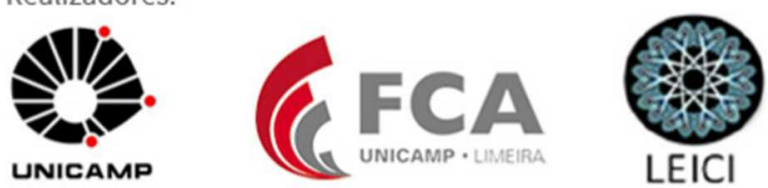
implementação de mecanismos de governança corporativa, sabendo que o processo impacta em pilares mais profundos da organização, causando várias transformações nas empresas.

\section{Referências}

ADACHI, Pedro Podboi. Família S.A: gestão de empresa familiar e soluções de conflitos. São Paulo: Atlas, 2010.

AMENDOLARA, Leslie. A sucessão na empresa familiar. 2 ed. São Paulo: Lazuli Editora, 2005. (Série Apimec).

ANDRADE, Adriana; ROSSETTI, José Paschoal. Governança Corporativa: fundamentos, desenvolvimento e tendências. 3. ed. São Paulo: Atlas, 2012.

BAYAD, M.; BARBOT, M-C. Proposition d'un modèle de succession dans les PME familiales: étude de cas exploratoire de relation père-fille. In: CONGRÈS FRANCOPHONE SUR LA PME, 6., AIREPME - Association Internationale de Recheche sur PME, TroisRivières, 2002.

BERNHOEFT, Renato. Empresa Familiar: sucessão profissionalizada ou sobrevivência comprometida. São Paulo: Nobel, 2005.

BORNHOLDT, Werner. Governança na empresa familiar: implementação e prática. Porto Alegre: Bookman, 2010.

CASILLAS, José Carlos; SÁNCHEZ, Adolfo Vázquez; FERNÁNDEZ, Carmen Diaz. Gestão da empresa familiar: conceitos, casos e soluções. Tradução de Vértice Translate. São Paulo: Thomson Learning, 2007.

GERSICK, Kelin E. et al. De geração para geração: ciclos de vida da empresa familiar. Tradução de Nivaldo Montingelli Jr. São Paulo: Negócio Editora, 1997.

LEONE, Nilda Maria de Clodoaldo Pinto Guerra. Sucessão na empresa familiar: preparando as mudanças para garantir sobrevivência no mercado globalizado. São Paulo: Atlas, 2005.

LIMA, Juvêncio B.; BORGES, Alex F.; CARVALHO, Flaviana A. P. Construção do Processo de Sucessão em Empresas Familiares: Transmissão Gerencial e Patrimonial. Rio de Janeiro: ANPAD, 2007.

LODI, João Bosco. A empresa familiar. 5. ed. São Paulo: Pioneira, 1998.

OLIVEIRA, Djalma de Pinho Rebouças. Empresa familiar: como fortalecer o empreendimento e otimizar o processo sucessório. 4 ed. São Paulo: Atlas, 2012.

RICCA, Domingos. Sucessão na empresa familiar: conflitos e soluções. São Paulo: Editora CLA, 2007.

SHARMA, P.; CHRISMAN, J.J.; CHUA, J.H. Strategic management of the family business: past research and future challenges. Family Business Review, v.10, n.1, 1997. p.1-35.

ST-CYR, L.; INOUSSA, R. La planification de la relève dans la PME: revue de la littérature et aveneues de recherche. In: CONGRÈS INTERNATIONAL FRANCOPHONE -SUR LA PME, 5., 2000, Trois-Rivières.

TONDO, Cláudia (Org.). et al. Desenvolvendo a empresa familiar e a família empresária. Porto Alegre: Sulina, 2008.

WERNER, René A. Família \& Negócios: um caminho para o sucesso. Barueri, SP: Manole, 2008.
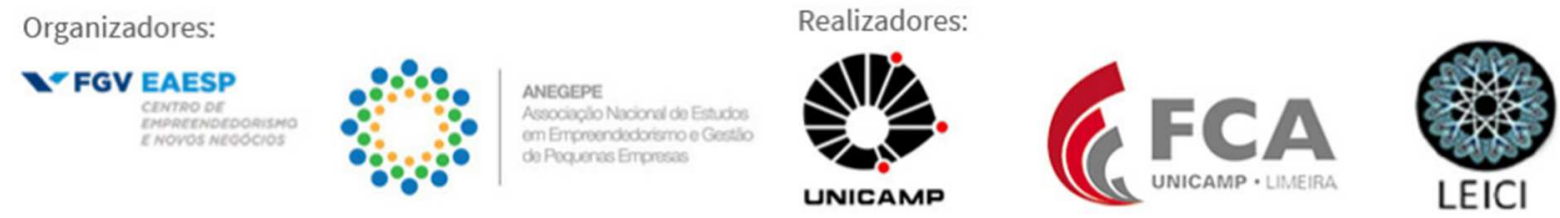